\title{
In defence of clinical bioethics
}

\author{
John D Arras Montefiore Hospital and Medical Center, New York \\ Thomas H Murray The Hastings Center, Hastings-on-Hudson, New York
}

In the course of his attack on the discipline of bioethics Professor Swales attempts to establish two conclusions. First, he argues that medical ethics cannot be dissociated from clinical decisions and should not, therefore, be taught as a separate subject in the medical curriculum. Medical ethics is 'too important', he says, to have its own separate place in the curriculum. Given this ringing affirmation of the importance of ethics for clinical practice, one would reasonably expect Swales's second conclusion to be that we must now proceed to develop a clinically-based medical ethic - ie an approach that would combine the conceptual sophistication of contemporary ethical theory with an appreciation of the empirical details of clinical practice. It comes as something of a surprise, then, when Swales's attack on the alleged separatism of bioethics turns into an attack on the very possibility of applying ethics to medicine. Since ethics in the world according to Swales is generally regarded as nothing more than sectarian, non-scientific speculation, he concludes that bioethics cannot be fruitfully applied to the moral dilemmas that beset contemporary medical practice. Lest today's physician be left without a moral compass of any sort, however, Swales hastens to add that a hard-headed, pragmatic utilitarianism - seasoned by years of medical experience - can serve as a guide to the perplexed physician. This endorsement of an instrumentalist ethical theory meshes nicely with Swales's conviction that all ethical questions in medicine are ultimately reducible to questions of technical expertise.

Although Professor Swales's unfavourable portrait of medical ethics bears scant resemblance to the discipline of bioethics as we know it, his dichotomous distinction between the 'two cultures' of medicine and ethics is sufficiently widespread in the medical community to merit a reply. Swales's indictment of contemporary ethics founders on a misunderstanding of the nature of ethics, of the interrelation of ethical and scientific considerations in clinical judgment, and of the role of the medical ethicist in the clinical setting.

\section{Key words}

Medical ethics; bioethics; medical education; patients' autonomy; ethicists.

\section{The nature of ethics}

First we should simply say that the opposition portrayed between medicine and medical ethics as parallel to that between science and religious ethics amounts to a caricature of both the latter enterprises. Science is not merely an inductive ingathering of empirical facts, but an immensely more complex and more interesting affair, bristling with idiosyncratic hypotheses and other 'subjective' elements. Many eminent philosopher-historians of science have argued that all of our theories necessarily presuppose a certain prescientific parti pris - a certain way of viewing the world - and have consequently ruled out the very possibilityo of any clear 'direct observation' of nature un-mediated by the tinted 'lenses' of our competing theories ( $\mathrm{I}$ ) Science is not nearly as concrete and anti-metaphysica as Swales's outdated portrait of it suggests. Good science requires the same sorts of judgments and rational arguments as good work in ethics.

Likewise, Swales does little justice to theological ethics by portraying it as amounting to nothing more than a dogmatic appeal to indefensible sectarian beliefs. At the least, this caricature ignores the extent to which secular and theological ethics have converged in defence of similar (but not identical) values, such as fidelity between physician-researchers and patients, the fostering of patients' welfare, and the rights of patients to self-determination and autonomous decision-making. Swales consequently obscures the enormous contributions of theological ethicists (such as Paul Ramsey, Joseph Fletcher, James Gustafson and Richard McCormick) to contemporary secular debates over such issues as genetic engineering, human experimentation, and the cessation of so-called 'extraordinary' medical treatments. If medical ethics amounted to nothing more than the recitation of indefensible maxims, and if ethical expertise were equivalent to the skills of the advertising man who cons us into buying one kind of soap rather than its indistinguishable competitor, then Swales would be correct, and the ethicist would have no more business in the clinic than the carnival barker. But religious medical ethics and, $a$ fortiori, contemporary secular ethics amount to much more than Swales would have us believe.

In fairness to Professor Swales and those who share 
his views, we must concede that some of the literature on medical ethics does seem to portray the enterprise as a facile invocation of remote and abstract ethical principles to specific issues: G E Moore on informed consent, Leviticus on prenatal surgery, or, as Professor Swales appears to prefer, Bentham on terminating treatment. His remarks on the meaninglessness of ethical expertise - or at best its irrelevance to clinical practice - would be well taken if medical ethicists did nothing more than recite from grand theories. But sound ethical inquiries in medicine are not like this at all.

Consider, for example, the nature of the principles that bioethicists habitually apply to the doctor-patient relationship. In response to an antiquated and narrowly professional Hippocratic ethic, contemporary bioethicists have enshrined the 'principle of autonomy' as the centrepiece of their emerging theory of how patients and physicians should relate to one another. A firm principle has gradually emerged from the convergence of various ethical traditions to the effect that medical decisions concerning the lives of patients properly belong to those patients, and not to physicians, no matter how knowledgeable or wellintentioned the latter might be. This principle of selfdetermination draws support from a wide variety of disparate ethical and religious traditions: from Kantian notions of autonomy and dignity, from the Utilitarians' conviction that the greatest good is best served by allowing each person to decide what is in his or her best interests, from the Lockean theory of natural rights, and from the Judeo-Christian teaching on the uniqueness and preciousness of each individual human being. Diverse as their ultimate first principles might be, each of these 'grand theories' lends support to the more modest middle-level proposition that, in the absence of compelling countervailing reasons, individual selfdetermination should prevail, even in the face of contrary medical advice.

Although the principle of autonomy occupies by far the most important place in the constellation of bioethical principles, several other middle-level principles have been articulated to guide the moral deliberations of health professionals and health planners. These include the principles of non-maleficence, beneficence, justice, veracity, and confidentiality (2). Thus, one perfectly respectable view of this emerging field holds that 'doing medical ethics' should (and often does) consist in the identification, articulation, and application of such convenient middle-level principles to concrete situations.

This conception of the relationship between ethical theory and practical application has undoubtedly achieved the status of a reigning paradigm in the bioethics community, but it is by no means the only available self-understanding of what bioethics is or should be about. An intriguing alternative is currently being explored by Albert $\mathbb{R}$ Jonsen and Stephen Toulmin (3). These philosophers take the usual presumed order (from principles to cases) to be mistaken, or at least greatly oversimplified. Our clearest and surest ethical judgments, they claim, are often about cases. In fact, novel cases often cause us to modify our principles; this is how much argument actually proceeds, even in theoretical ethics. If we understand Jonsen and Toulmin correctly, they conceive of ethics in practice as a dialectical process of 'casuistry', wherein principles are fashioned and modified largely in response to their ability to articulate our intuitive responses to particular cases. Once again, the working principles are at the middle level; much of the work of practical ethics consists in identifying which principle or principles are most important or fruitful in the particular case. Whether we prefer principle-ethics or case-ethics (approaches that might well merge in practice), both require careful attention to concrete details, and both involve more than the vacuous incantations of abstract principles that Swales mistakenly identifies as ethics.

\section{The intersection of clinical judgment and moral judgment}

Assuming that ethics is net the spooky metaphysical business that Swales makes it out to be, exactly how are we to conceive of the relationship between clinical judgment and moral philosophy?

Swales appears to be of two minds concerning the possibility of a fruitful collaboration between morals and medicine. In the first part of his essay, he maintains that ethical decisions in medicine cannot be dissociated from clinical decisions, adding (rather disingenuously, in our opinion) that medical ethics is 'too important' to be taught separately. But in the remainder of his essay, Swales adamantly declares that medicine is science, medical ethics non-science, and never the twain shall meet. One is left wondering how two inseparable subjects can have nothing to do with one another. Perhaps our perplexity will abate upon closer examination of Swales's (apparently) contradictory assertions.

First, what does Swales mean when he claims that medical ethics cannot be dissociated from clinical decisions? The least he could be claiming is that medical ethics necessarily or essentially concerns itself with medical decisions, just as business ethics is about business, or engineering ethics about engineering. This claim is true, but only because it is a tautology; as such, it does not tell us whether it is either possible or desirable to teach medical ethics as a separate subject.

A more interesting interpretation of the essential connection between medical ethics and clinical decisions would assert that theory construction in medical ethics must draw on a knowledge of medical facts and medical practice. Few, if any, practising bioethicists would take issue with this claim. Indeed, they would assert that good work in bioethics must be firmly anchored in the medical facts. Still, this belief in no way implies that the theories and methods of medical ethics cannot be presented apart from the clinical setting. It may or may not be pedagogically desirable to 
teach medical ethics as a separate subject but it is certainly possible to do so.

So we are left with a much stronger and much more controversial interpretation that alone seems to capture what Swales has in mind: medical ethical judgments cannot be separated from clinical or technical judgments because they cannot be distinguished conceptually as two distinct sorts of judgments. In other words, medical ethical decisions are clinical decisions. Contrary to the previous interpretations, this one is neither tautologous nor platitudinous; it is, however, plainly false.

Swales attempts to support this contention by noting that ethical and clinical decisions frequently masquerade as each other. It is true that a good deal of masquerading goes on in the hospital setting; doctors often cloak their moral advice to patients in the language of medicine, and bioethicists are often called upon to discuss problems that turn out, on close examination, to be largely medical (4). But Swales cannot support his sweeping implication that all medical ethical issues are really clinical by alluding to these occasional transformations. Although moral concerns pervade clinical decisions, they can nevertheless be distinguished from the merely technical. The occasional case in which a question of medical management poses as an ethical issue does not demonstrate that all medical ethical issues are really at bottom clinical. No amount of medical knowledge can tell us whether the Jehovah's Witness is morally entitled to refuse a blood transfusion, whether a woman with breast cancer should be able to choose between a radical mastectomy and lumpectomy, or whether severely defective neonates should have to make way for healthier babies in an overcrowded intensive care unit (ICU). Doctors must provide much-needed medical knowledge bearing on such questions, but medical data alone will never determine the 'solutions' to these moral dilemmas. Problems such as these highlight the fact that, while ethical issues might well be firmly embedded in the clinical setting, these clinical decisions are themselves embedded in the larger human context where such moral concerns as truthtelling, personal autonomy and justice hold sway. These larger ethical concerns form the warp and woof of contemporary biomedical ethics.

After having argued that ethical and clinical decision-making cannot be dissociated, Swales performs an about-face, declaring that no matter how earnestly bioethicists try to acquaint themselves with the medical facts, they will never be able to 'throw light on what we [doctors] should do'. This, he says, is because ethics is essentially metaphysical or religious, while medicine proceeds according to a scientific method. Here Swales seems to be arguing that ethics is so easily distinguished from medicine that it is actually irrelevant to it!

As we have already seen, this attempted assimilation of ethics to religion is based on a seemingly complete ignorance of the discipline of secular ethics and on an unjustified devaluation of religious ethics. Neverthe- less, Swales makes other points here that merit a response. While he insists that non-scientific outsiders can contribute nothing to clinical decision-making, Swales does grant a certain validity to a utilitarian ethic espoused by many in the medical community. This ethic is concerned exclusively with 'doing good' - ie with maximising the welfare of the patient. And since an accurate appraisal of the patient's welfare must rest upon a knowledge of the medical alternatives, Swales concludes (rather hastily) that only physicians are in a position to make this sort of ethical judgment.

This contention is vulnerable even if we assume the validity of an exclusively pragmatic or patientbenefiting ethic in the Hippocratic tradition. Such an ethic, if it is to be anything more than a mere diagnostic and treatment manual, must be geared to the total welfare of the patient - not simply to her medical condition narrowly construed, but also to her emotional, psychological, and socioeconomic conditions as well. Thus, in deciding, for example, whether or not to tell a cancer patient the truth, the doctor must know about the patient's own hopes, fears, plans and problems in order accurately to predict what course will, in fact, maximise her welfare. This sympathetic identification and weighing of needs, preferences, and (sometimes) idiosyncratic values is no doubt a much more difficult undertaking than Swales would have us believe; but even more importantly, such a task is plainly not a matter of medical or technical expertise. Doctors have no special training to do it; and they are often pretty bad at it - (not, we hasten to add, because: they are unusually insensitive to psychosocial considerations, but rather because of their own predisposition to treat patients in certain ways and because of the increasingly anonymous character of doctorpatient interactions in large hospitals and nursing homes today). A knowledge of the technical options is obviously necessary to make informed decisions, but it is not sufficient to calculate the patient's best interests. To do that, one would have to factor in all sorts of hazy, non-scientific variables such as the patient's attitude toward cosmetic appearance, aversion to risk, etc.

Apart from these problems which are internal to Swales's pragmatic medical ethic, there are good reasons for rejecting any medical ethic that is blind to such themes as patients' rights, self-determination, truthtelling, and confidentiality. Even if most doctors were to develop the necessary counselling skills to work up an accurate and complete psychological profile of each patient, upon which they could base their judgment of 'best interests', we would still think that the patient retains the right to decide for herself what should be done by others (including doctors) to her body. We would say that she exercises this right because of her moral status as an autonomous, selfdetermining person. Thus, even if the welfare of a patient would seem to require a blood transfusion, the patient retains the moral and legal right to refuse such a procedure. Thus, Swales's bald assertion that 'the welfare of the patient is paramount' would have to be 
complemented by an equally sensitive concern for patients' rights.

In fact, anyone familiar with the development of contemporary biomedical ethics would realise that this cluster of rights emanating from the notion of patients' self-determination has provided the basis for an expressly covenantal or contractual patient-centred medical ethics that has produced rather impressive results in the last decade. Contrary to Swales's claim that contemporary bioethics has not had any noticeable effect on medical practice - a claim based on an embarrassingly faulty analogy between ethics and the philosophy of science - the impact of bioethics on issues of private and public health policy has been significant and far-reaching at least in the USA. Although bench scientists may not have changed their behaviour to suit the theories of Hempel, Kuhn and Popper, doctors have dramatically altered their behaviour in recent years. While some of these changes can and should be attributed to larger cultural forces at work on the medical community, it is hard to believe, for example, that the advent of a reinvigorated discipline of medical ethics had nothing to do with physicians' changed attitudes toward truthtelling to patients with cancer (5). Other examples of the impact of bioethics - eg in the fields of human experimentation, death and dying, genetic screening and behaviour control - could be multiplied indefinitely.

All this has been mere brush-clearing, to establish the possibility of a fruitful collaboration between ethics and medicine despite their familial resemblances to the humanities and the sciences, respectively. Proof that practitioners of the two arts can benefit from each other's skills, and especially that the patient can also, must come from the actuality of practice.

\section{The role of the bioethicist}

If we accept that the application of ethical reasoning to moral problems in medicine can be done in a sophisticated, non-dogmatic fashion, we must still ask what role or roles the medical ethicist can play in interaction with other actors in the medical drama. Consider two contrasting prototypes: the 'moraliser' and the 'analyser'. Swales seems to view the medical ethicist as necessarily a moraliser - a person whose self-conceived role is to pass moral judgment on the actions of those around him, or her, usually (we might add) without giving any thought either to the rational foundations, if any, of his pronouncements, or to the ambiguities that plague most situations calling for a moral choice. Swales justifiably rejects this conception of 'moral expertise'; and if this were all that medical ethicists did, we would not defend them either.

At the opposite extreme from the moraliser is the 'analyser' - a person whose expertise consists in identifying the values implicated by various choices, charting the implications of these choices for other values that people might hold, and assessing the logical coherence of the arguments offered on behalf of ethical choices. Whereas the moraliser wastes no time in rushing to a moral judgment, the analyser self-consciously refrains from making any moral judgments, resting content to clarify the moral issues and expose fallacious reasoning. Repelled by the notion that his job is to tell other people how to behave morally, the analyser would most likely disown the title of 'moral expert'.

While we know of no one doing medical ethics seriously who subscribes to the moraliser prototype, many do believe in some version of the analyser. We hold neither view to be adequate. Each contains elements of a more complete medical ethic, but neither can stand alone. The ethicist as moraliser is a parody of serious work in medical ethics; the ethicist as analyser places unnecessary limits on the kinds of work that need to be done. Let us illustrate with a case.

Recently one of us encountered a comatose middleaged woman in an intensive care unit whose best hope, however slender, was to emerge severely braindamaged, having lost both legs, an arm, and the remaining hand. Although some discussion had taken place regarding the continuation of the massive efforts required merely to stabilise her debilitated condition, no one was willing to take responsibility for talking with the family about the possibility of discontinuing the aggressive treatments she was currently receiving.

The problem facing the house staff and the nurses was what to do about the patient's surgeon. During the course of the unsuccessful operation the surgeon had apparently made a forgiveable error, setting off a cas-흐 cade of unfortunate medical complications, and had subsequently withdrawn both from the woman's family and from the other medical staff involved in the case. As a result, the agonising task of communicating with the family fell to the nurses and house staff.

A responsible ethicist could make confident moral judgments about certain features of this case, but about other things he might only be able to engage in a dialogue with the family and staff, helping them all to muddle through. A clinical ethicist should have no trouble concluding, for example, that the family must be brought into a dialogue regarding this patient's future course of treatment (or non-treatment). Appropriate family members should be forthrightly (but sensitively) appraised of the patient's dire condition, dismal prognosis, future quality of life, and the remaining medical options. Assuming that they wish to decide and that they will base their decision on the patient's best interest, the family should be allowed to determine whether 'aggressive' treatments should be employed further to prolong the patient's life. The 'moraliser' model permits the bioethicist to pass moral judgments when there is a clear understanding that some important standard of ethical conduct has been violated. In this case, the surgeon's behaviour placed an unfair burden on the other medical staff, and added to the terrible burden borne by the patient's family. What happened in this case, was that the patient's family indicated, when finally approached, that they would be willing to care for her no matter what her con- 
dition, so long as she could rejoin them at home. A tragic choice, but one which must be sensitively attuned to the values of the woman and her family, and based on the best medical knowledge available.

A case of another woman with similarly bleak prospects was further complicated by the intransigent stance taken by one of the first-year surgical residents involved in the woman's care. This young physician was scandalised by the prospect of allowing his patient to die. 'I think we must keep her alive', he asserted, 'that's what the medical profession is all about. That's what I've been trained to do'. The resident went on to argue that a decision to withdraw 'aggressive' therapy from the patient would be tantamount to killing her. Here, we would argue, is an ideal occasion for the ethicist-as-analyser to make an appearance. Either during the case consultation itself or (more likely) in subsequent teaching rounds, the ethicist can aid clinical decision-making through a sophisticated, yet clear, analysis of the conceptual and moral differences between 'killing' and 'letting die' in various circumstances. We think it highly desirable that this sort of reflective analysis replace the mere repetition of slogans - 'Saving life is our job' - especially when the unreflective parroting of such maxims can lead to increased pain and suffering for patients and their families.

Thus, we prefer to think of the medical ethicist as a person skilled in moral reasoning and schooled in the medical and psychological realities of the clinic, whose primary function is to engage all concerned in serious and clear reflection upon the moral dimensions of their work. Sometimes this task will require the ethicist emphatically to remind a physician that adult patients of sound mind have a right to determine what shall be done to their bodies; at other times it will require the application of analytical skills to conceptual and normative problems. But beyond these two functions of the 'moralist' and the 'analyser', we see a third role for the ethicist in the hospital: as a diagnostician of the 'deep structure' of ethical dilemmas. Just as a good physician might attempt to relate reported symptoms to an underlying biochemical cause, a perceptive ethicist should be alert to the possible institutional causes of the ethical dilemmas that present themselves in the medical context. Rather than resting content with a model of the ethicist as a 'moral engineer' (6) - ie, as someone who applies the tools of ethical analysis to problems precisely as they are presented by the medical staff - we believe that the ethicist should view the staff's presentation of a dilemma as one bit of information fitting into a larger picture. Often enough, the particular form in which a problem is presented will either badly misconstrue the actual problem or tend to obscure the underlying organisational reasons for the dilemma's appearance. Take, for example, the problem of triage within a medical ICU. The dilemma of 'whom to save when not all can be saved' is certainly one of the most difficult and persistent ethical problems faced by hospital-based ethicists; yet, as they grapple with the 'tragic choice' of who ought to get the last bed in the ICU, ethicists should also ask themselves why this bed happens to be the last one. Is it because the hospital administration has allocated insufficient resources to its ICU? Or is it the last bed because on the medical director of the ICU exercises insufficient $\bar{T}$ control over who gets in and who goes out? Perhaps the ethicist will discover that the problem of chronic overcrowding - and thus the dilemma posed by triage - $\overparen{\mathbb{D}}$ could be alleviated by a more enlightened policy of giving only 'supportive' care to those patients who are truly beyond the pale of aggressive measures.

One of us has spent a good deal of time with a particular hospital intensive care unit. Its director had $\omega^{\circ}$ requested our help in dealing with some thorny ethical dilemmas which, he said, were a source of continuing $\overparen{Q}$ divisiveness among nurses and physicians. We found that, although the staff was indeed confronted by perplexing ethical problems, the source of dissension had $N$ more to do with the manner in which physicians 0 (including inexperienced house staff) related to the nurses, who often knew much more about appropriate $\infty$ treatments than the neophyte doctors. In this case, an $\frac{\mathbb{D}}{0}$ 'ethical engineer' would have accepted the diagnosis as presented by the director and thus would have overlooked the real source of dispute. Although we agreed to analyse the ethical dilemmas themselves, we also insisted upon discussing the organisational and pep sonal problems that served to exacerbate the staff difficulties in resolving the ethical disputes.

\section{Conclusion}

As long as medical decisions are about human beings and the kinds of lives they will lead - or leave - those decisions will be inextricable mixtures of medical, scientific and moral considerations. In most cases, no great ethical dilemmas emerge, and both doctor and patient can get on with their affairs without the aid of a bioethicist. But when those dilemmas do arise, or when common medical practices rest on dubious moral $\bar{\sigma}$ grounds, it is handy to have a bioethicist around. Not to make the decisions, certainly, but to improve the dialogue, to help doctors to appreciate the moral complexities of their vocation, and, in the tradition of one $ᄋ$ of the first 'ethicists', to be the horsefly biting the rump of the Athenian (or Hippocratic) steed when needed.

\section{References and notes}

(I) Kuhn T S. The structure of scientific revolutions, 2nd $\stackrel{N}{N}$ edition. University of Chicago Press, 1970; Hanson N R. W Patterns of discovery. London: Cambridge University Press, 1958; Feyerabend P K. Against method. London: $c$ Verso, 1978; and Koestler A. The sleepwalkers. New York: Grosset and Dunlap, 1963.

(2) See generally Beauchamp T, Childress J. Principles of biomedical ethics. New York: Oxford University Press, $\mathrm{O}$ 1979.

(3) Jonsen A R. Can an ethicist be a consultant? In: $\frac{\mathcal{Q}}{\mathbb{T}}$ Abernethy V, ed. Frontiers in medical ethics: applications $\varrho$ in a medical setting. Cambridge: Ballinger, 1980; 
Toulmin S. The tyranny of principles. Hastings Center report December $198 \mathrm{I}$.

(4) We are, however, a bit puzzled by Swales's contention that the case of Leonard Arthur exhibits this 'shift from the ethical to the clinical domain'. If the practice of 'allowing the deaths' of anomalous newborns is not a moral issue, what is? If the crucial question raised by this case called for clinical, rather than moral, expertise, why did the members of LIFE press the issue in court? For a sensitive discussion of the Arthur case, see Glover J. Letting people die. London Review of Books 4-I 7 March I982; Vol 4 No 4: 3.

(5) Veatch R M, Tai E. Talking about death: patterns of lay and professional change. The annals of the American Academy of Political and Social Science January 1980; 29-45; and Novack D H et al. Changes in physicians' attitudes toward telling the cancer patient. Fourmal of the American Medical Association March 2, 1979; 24I: 897-900.

(6) Caplan A L. Ethical engineers need not apply: the state of applied ethics today. Science, technology and human values Autumn I980; 6: 24-32.

\section{Response}

\section{J D Swales School of Medicine, University of Leicester}

I am flattered that my short piece drew forth such lengthy rejoinders. I am also delighted because in spite of the assertions made in these replies I believe that a debate between individuals of the widest range of backgrounds is a desirable and necessary precondition to finding a working provisional solution to the ethical dilemmas of medicine. My objection was not to such a debate. My objection was to the development of the 'ethical expert' and the discipline of 'medical ethics' as a discrete subject in the teaching of medical students analogous say to endocrinology or gastroenterology.

The implication of Arras and Murray that ethical value judgments and the inductive observations and testable hypotheses of medical science are qualitatively similar hardly stands up to critical examination (I). Do they seriously believe that the ethics of, for instance, the termination of pregnancy are testable in the same way as, say, those of clinical treatment? If ethical hypotheses were testable I would agree that analogous roles for the ethicist and endocrinologist could indeed be identified. Until I am convinced of this the arguments for 'professional ethicists' remain specious.

I might be persuaded by the more empirical approach of demonstrating benefit. I certainly am not persuaded by statements referring to 'Swales's conviction that all ethical questions in medicine are ultimately reducible to questions of technical expertise' or the statement that 'he [Swales] insists that non-scientific outsiders can contribute nothing to clinical decisionmaking . . . I recognise that it is easier to attack a stereotype of an intensively conservative medical position, but nowhere in my article or elsewhere have I objected to a wider debate with non-medical interested parties. However, I would emphatically give primacy in such debate to patients rather than 'experts' or pressure groups with a particular viewpoint and it is depressing that both replies give so much space to the role of various experts and so little to the role of the patient which I emphasised in my original piece. I would have hoped that from their experience Arras and Murray could have produced evidence for the value of the 'bioethicist'. Unfortunately they have not. Indeed we are merely assured that 'it is hard to believe' that changes in doctors' approaches have not been influenced by bioethicists. The examples they quote do not support this view. The justifiable concern with human experimentation in the United Kingdom, for instance, does not follow from ethicists' investigation. It largely stems originally from Dr Pappworth's book (2) which meticulously chronicled published studies in the medical literature and explained for a lay public what was involved. Ethical judgment was clearly necessary but equally clearly no expert moral analysis was required to demonstrate the unacceptable nature of what was being done. The relevant previously unrecognised fact was that it was happening. It is as illogical to claim that public concern with the dilemmas of medicine follows from the evolution of bioethics as it is to maintain that the equally widespread concern with the modern epidemic of cardiovascular disease stems from the development of professional cardiologists. Post hoco non propter hoc.

Most disturbing of all in Arras and Murray's article is the description of an expansion of the role of the ethicist into a social worker/psychotherapeutician who knows 'about the patient's own hopes, fears, plans and problems in order accurately to predict what course will in fact maximise her welfare'. I am even more surprised to read that this is 'a more difficult undertaking than Swales would have us believe', since my original article expresses no views about this difficult area. Further, in the last paragraphs, a role in analysing organisational and personal problems of staff and patients is described which suggests quite different activities from those which the term 'ethical philosophy' would normally subsume. Such activities should be judged in their own right but have no bearing on my original contention.

Since the burden of my article has clearly escaped Drs Arras and Murray perhaps I could emphasise again the importance of an open debate. What I remain sceptical about is the role of the ethicist as an expert whose authority can resolve the dilemmas of medicine for ourselves and our students. Judging by the analysis presented by Drs Arras and Murray it cannot do this, it can however generate a considerable smoke-screen.

\section{References}

(I) Popper K R. The logic of scientific discovery. London: Hutchinson, I 977.

(2) Pappworth M H. Human guinea-pigs: experimentation on Man. London: Routledge \& Kegan Paul, 1967. 